\title{
Sosialisasi Computational Thinking untuk Guru-Guru di SDN Teluk Dalam 3 Banjarmasin
}

\author{
Muhammad Edya Rosadi ${ }^{*}$, Wagino ${ }^{1}$, Nur Alamsyah ${ }^{1}$, Muhammad Rasyidan ${ }^{1}$ dan Mirza Yogy \\ Kurniawan ${ }^{1}$ \\ ${ }^{1}$ Universitas Islam Kalimantan Muhammad Arsyad Al Banjari Banjarmasin, J1. Kayu Tangi 1 Jalur 2 No.2, \\ Sungai Miai, Kota Banjarmasin, Kalimantan Selatan, Indonesia, 70123 \\ Email: edya.rosadi@gmail.com
}

\begin{abstract}
Abstrak
Computational thinking atau yang disebut juga berpikir komputasi adalah sebuah istilah untuk melatih kemampuan memecahkan masalah dengan cara penalaran dan analisa, sekarang ini banyak yang beranggapan bahwa berpikir komputasi harus selalu berkaitan dengan komputer. Kenyataannya, berpikir komputasi bukan mengajarkan cara menggunakan komputer tetapi mengajarkan proses berpikir yang digunakan untuk mendukung pemecahan masalah di semua disiplin ilmu, termasuk humaniora, matematika dan ilmu pengetahuan. Berpikir komputasi dapat diajarkan sejak dini bahkan dari tingkat Sekolah Dasar (SD) dengan cara membuat hubungan pada suatu mata pelajaran atau dengan memberikan contoh penyelesaian persoalan sederhana yang terdapat pada kegiatan sehari-hari. Melalui pengabdian kepada masyarakat ini, disosialisasikan kepada para guru Sekolah Dasar Negeri (SDN) Teluk Dalam 3 Banjarmasin tentang berpikir komputasi, bertujuan agar guru dapat menambahkannya ke dalam mata pelajaran yang diampu, sehingga siswa dapat terbiasa memecahkan masalah dengan cara berpikir komputasi, yang mana ketika kemampuan ini terus dilatih maka sebuah permasalahan dapat diselesaikan dengan baik, cepat dan optimal.
\end{abstract}

Kata kunci: computational thinking, guru, sekolah dasar, sosialisasi

\begin{abstract}
Computational Thinking is a term to exercise problem solving skills by analysis and reasoning method, now many people assume that having computational thinking should always related to computer. In fact of this, computational thinking does not teach how to use computer but teach thinking process which is used for supporting problem solving in all of disciplines, include humanism, math and science. Computational thinking can be taught since the early moreover at the Elementary School by making correlation in a subject or giving the example of a simple problem solving in daily life. Through this community dedication, the teachers of Sekolah Dasar Negeri (SDN) Teluk Dalam 3 Banjarmasin are socialized how to think computationally, it is intended that the teachers can add it in their teaching subjects, then the students will be able to accustomed in solving problems with computational thinking, when this ability is constantly trained then a problem can be solved well, fast and optimum.
\end{abstract}

Keywords: computational thinking, teachers, elementary school, socialization

Format Sitasi: Rosadi, M.E., Wagino, Alamsyah, N., Rasyidan, M., \& Kurniawan, M.Y. (2020). Sosialisasi Computational Thinking untuk Guru-Guru di SDN Teluk Dalam 3 Banjarmasin. Jurnal SOLMA, 09(1), 45-54. Doi: http://dx.doi.org/.10.29405/solma.v9i1.3352

Diterima: 30 Maret 2019 | Revisi 12 Desember 2019 | Dipublikasikan: 30 April 2020

(C) 2018 Oleh authors. Lisensi Jurnal Solma, LPPM-Uhamka, Jakarta. Artikel ini bersifat open access yang didistribusikan di bawah syarat dan ketentuan Creative Commons Attribution (CC BY) license. (http://creativecommons.org/licenses/by/4.0/). 


\section{PENDAHULUAN}

Dokter, pengacara, guru, petani, dan apapun profesinya di masa depan akan sepenuhnya diisi oleh computational thinking, baik itu berupa obat berbasis sensor, kontrak komputasional, analisis kependidikan, pertanian komputasional, kesuksesan akan bergantung kepada kemampuan menggunakan computational thinking dengan baik (Wolfram, 2016). Revolusi industri 4.0 merupakan istilah yang mengaitkan segala proses produksi kepada internet sebagai penopang utamanya. Semua objek akan dilengkapi dengan sensor tertentu sehingga mampu melakukan komunikasi secara mandiri kepada sistem teknologi informasi (Prasetyo \& Sutopo, 2018). Industri 4.0 menyebabkan nyaris seluruh aspek kehidupan terkait dengan sistem komputer, seluruh kegiatan memiliki sistem informasinya masing-masing, tidak hanya bidang teknik, melainkan juga sampai dengan bidang sosial. Kondisi ini menuntut seluruh tenaga kerja tidak hanya ahli dalam bidangnya, tetapi juga ahli dalam hal berpikir komputasi (computational thinking).

Pada awalnya pengertian computational thinking merupakan sebuah pendekatan dalam proses pembelajaran yang memiliki peran penting dalam pengembangan aplikasi komputer. Dalam perkembangannya computational thinking tidak hanya berkaitan dengan pengembangan aplikasi komputer, namun berubah menjadi suatu proses berpikir. Menurut Wing (2006). Computational thinking adalah kemampuan intelektual dalam menyusun persoalan dan solusinya, sehingga solusi tersebut dapat secara efektif dilaksanakan oleh agen pemroses informasi baik itu manusia, robot, atau bahkan komputer.

PISA (Programme for International Student Assessment) merupakan salah satu cara mengukur keberhasilan sistem pendidikan tingkat dasar sampai dengan menengah di bidang sains, membaca, dan matematika (Wijanto et al., 2019). Berdasarkan hasil test PISA (2015) didapati bahwa kemampuan siswa di Indonesia berada di bawah rata-rata nilai internasional sehingga menurut Sukamto et al., (2019) siswa Indonesia perlu mendapatkan kemampuan yang tidak hanya terkait dengan membaca, menulis, dan aritmatika, meskipun sebenarnya menurut Calao, Leon, Correa, \& Robles (2015) dan juga Weintrop et al., (2016) kemampuan matematika berkaitan erat dengan computational thinking. Salah satu cara memperkenalkan dan memunculkan sifat-sifat anak berpikir computational thinking adalah dengan menggunakan media permainan, seperti yang sudah dikerjakan oleh Octavia (2019) dengan mengembangkan media pembelajaran dengan model pengembangan Analysis, Design, Development, Implementation, Evaluation (ADDIE) dan 
juga permainan yang dikembangkan oleh Syarifuddin, Risa, Hanifah, \& Nurussa'adah (2019) bernama GORLIDS (Algorithm for Life Kids).

Bebras adalah sebuah inisiatif internasional yang tujuannya adalah untuk mempromosikan computational thinking (berpikir dengan landasan komputasi atau informatika), di kalangan guru dan murid mulai kelas 3 sekolah dasar (SD), serta untuk masyarakat luas (Bebras Indonesia, 2018a). Secara harfiah, "Bebras" adalah kata dalam bahasa Lithuania, yang berarti "berang-berang" dalam bahasa Indonesia. Prof. Valentina Dagiene dari Universitas Vilnius, Lithuania adalah tokoh yang mencetuskan gagasan Bebras Computational Thinking Challenge, yang saat ini diikuti oleh kurang lebih 50 negara di dunia. Komunitas ini mengenal dan mengajarkan berpikir komputasi dengan beberapa contoh permasalahan yang disebut tantangan bebras. Tantangan bebras menyajikan soal-soal yang mendorong siswa untuk berpikir kreatif dan kritis dalam menyelesaikan persoalan dengan menerapkan konsep-konsep berpikir komputasional.

Menyadari pentingnya konsep berpikir komputasional untuk kalangan guru dan siswa sekolah, sejak tahun 2005, komunitas Bebras internasional (bebras.org) ini menggelar Tantangan Bebras (Bebras Challenge) secara periodik pertahun untuk mengedukasi konsep berpikir komputasional dan informatika kepada siswa sekolah pada berbagai tingkatan usia. Siswa yang mengikuti kompetisi Bebras biasanya dibimbing oleh guru dalam persiapan sebelumnya. Kompetisi dilaksanakan dalam jaringan (online) melalui komputer atau gawai. Kegiatan kompetisi ini dilaksanakan secara nasional oleh komunitas Bebras yang ada di negara yang bersangkutan. Setiap tahun, Bebras Internasional akan mengadakan workshop yang dihadiri oleh wakil komunitas Bebras dari setiap negara yang tergabung dalam komunitas Bebras, laman resmi Bebras Indonesia adalah bebras.or.id. Setiap soal Bebras mengandung aspek komputasi atau informatika dan dimaksudkan untuk menguji bakat peserta untuk berpikir komputasi atau informatika. Untuk menjawab soal-soal Bebras, secara alamiah, siswa dituntut untuk berpikir terkait dengan informasi, struktur diskrit, komputasi, pengolahan data, serta harus menggunakan konsep algoritmik.

Sekolah Dasar Negeri (SDN) Teluk Dalam 3 Banjarmasin adalah salah satu sekolah yang berada di komplek pendidikan Mulawarman Banjarmasin. Menurut laman Data Pokok Pendidikan Dasar dan Menengah, sekolah yang beralamat di Jalan Batu Damar No.5 Kecamatan Banjarmasin Tengah ini memiliki 32 orang guru atau pengajar, di mana jumlah tersebut menjadikan sekolah ini adalah sekolah dengan guru terbanyak di 
Banjarmasin. SDN Teluk Dalam 3 telah menerapkan Kurikulum 2013 (K-13) (Kementerian Pendidikan dan Kebudayaan, 2018). Penggunaan computational thinking pada kurikulum 2013 bukan untuk mempelajari kemampuan komputer, namun menjadi materi yang multi disiplin atau bisa masuk ke muatan pelajaran apapun, karena berbentuk soal-soal logika dan algoritmik, juga dapat dimasukkan ke bab manapun dalam suatu pelajaran. Tujuan kegiatan pengabdian kepada masyarakat tentang penggunaan computational thinking ini adalah untuk mendukung pemecahan masalah di semua disiplin ilmu, termasuk humaniora, matematika dan ilmu pengetahuan. Siswa yang belajar dimana computational thinking diterapkan dalam kurikulum (proses pembelajaran) dapat mulai melihat hubungan antara mata pelajaran, serta antara kehidupan di dalam dengan di luar kelas.

\section{MASALAH}

Computational thinking dapat diterapkan sejak dini, misalnya dari tingkat sekolah dasar (SD) melalui para guru yang mulai mengenalkan dan memasukkan contoh materi berpikir komputasi pada setiap pelajaran mereka ampu atau dengan penyelesaian permasalahan sederhana yang terjadi dalam kegiatan sehari-hari. Dengan membawa pemikiran komputasi ke dalam dunia pendidikan, dapat melatih dan membiasakan siswa menyelesaikan suatu masalah secara cepat dan terpola, keberhasilan siswa dalam menangani suatu masalah dapat meningkatkan kepercayaan diri siswa itu sendiri. Berdasarkan hasil kuesioner sebelum pengabdian, diketahui para guru belum mengenal apa itu berpikir komputasi (computational thinking) baik dari contoh soal ataupun mengimplementasikan ke mata pelajaran masing-masing. Melalui pengabdian ini, mitra yang merupakan guru SDN Teluk Dalam 3 diberikan sosialisasi mengenai berpikir komputasi dengan tujuan guru mendapat pemahaman lebih banyak dan dapat menambahkan materi berpikir komputasi pada mata pelajaran di sekolah.

\section{METODE PELAKSANAAN}

Agar tercapai perbaikan atau solusi dari masalah mitra di atas, maka dalam kegiatan pengabdian kepada masyarakat ini dilaksanakan dengan beberapa metode, antara lain:

\section{Ceramah}

Melalui metode ini disampaikan tentang Computational Thinking (berpikir komputasi) secara umum seperti pengertian, kendala, tantangan dan perkembangannya pada revolusi industri 4.0; kemudian disampaikan juga secara khusus penggunaan materi 
berpikir komputasi tingkat Sekolah Dasar beserta contoh-contoh laman internet (website) yang dapat digunakan anak-anak untuk belajar komputasi dasar seperti code.org, bebras.or.id dan wolframalpha.com.

\section{Praktik}

Metode ini diadakan setelah guru-guru menerima teori dari metode ceramah, para guru langsung disajikan contoh soal dan pembahasan Computational Thinking yang dapat digunakan untuk mendorong siswa untuk berpikir kreatif dan kritis dalam menyelesaikan persoalan sehari-hari. Pada sesi ini guru-guru akan didampingi langsung oleh tim dan mahasiswa yang dilibatkan dalam pengabdian ini.

3. Diskusi Aktif

Dengan metode ini peserta dapat langsung bertanya dan berdiskusi kepada tim pengabdian pada masyarakat yang mendampingi mereka selama kegiatan berlangsung. Selanjutnya untuk pengumpulan data dengan menggunakan kuesioner yang dibagi menjadi dua bagian yaitu kuesioner pra pengabdian dan kuesioner pasca pengabdian.

4. Evaluasi

Agar dapat mengetahui gambaran keberhasilan pengabdian ini dan perbaikan untuk pengabdian kepada masyarakat berikutnya maka dilakukan evaluasi dengan memberikan peserta pertanyaan-pertanyaan berbentuk kuesioner sebelum dan sesudah pelaksanaan pengabdian.

\section{HASIL DAN PEMBAHASAN}

Pelaksanaan pengabdian kepada masyarakat ini terlaksana pada hari Senin tanggal 10 Desember 2018 dari pukul 13.00 WITA sampai dengan 17.00 WITA dan dihadiri oleh 15 orang peserta yang merupakan guru dari berbagai mata pelajaran di Sekolah Dasar Negeri (SDN) Teluk Dalam 3 Banjarmasin. Pada awal kegiatan dibagikan kuesioner sebelum pelaksanaan pengabdian dengan hasil sebagai berikut:

Tabel 1. Hasil kuesioner pra-pengabdian

\begin{tabular}{ccc}
\hline Jenis Komponen & Jawaban & Jumlah Pemilih \\
\hline Mengenal computational thinking & Sudah & 2 \\
Menerapkan computational thinking & Belum & 13 \\
Mempunyai komputer sendiri & Sudah & 1 \\
& Belum & 14 \\
Menggunakan komputer saat mengajar & Punya & 15 \\
& Tidak & 0 \\
Kemampuan penguasaan komputer & Sudah & 13 \\
& Belum & 2 \\
& Sangat Menguasai & 1
\end{tabular}




$\begin{array}{ccc} & \text { Biasa } & 6 \\ & \text { Kurang Menguasai } & 2 \\ \text { Jumlah Peserta } & \text { Tidak Menguasai } & 0 \\ & & \mathbf{1 5}\end{array}$

Dari kuesioner pra-pengabdian didapatkan hasil, hanya 2 dari 15 guru yang mengenal computational thinking, dari 2 guru tersebut, 1 guru pernah menerapkan computational thinking dalam mata pelajarannya. Ditinjau dari sumber daya yang ada, semua guru telah mempunyai komputer atau laptop sendiri dan sebanyak 13 guru pernah menggunakan komputer saat mengajar. Selain itu, menurut penilaian pribadi untuk menilai kemampuan menggunakan komputer sebanyak 1 guru sangat menguasai, 5 guru menguasai, 6 guru dengan kemampuan biasa dan 2 orang guru merasa masih kurang menguasai menggunakan komputer. Kesimpulannya dari sumber daya dan kemampuan guru seharusnya dapat menerapkan materi computational thinking saat mengajar, namun karena banyak guru yang belum mengenal sehingga belum dapat menerapkannya. Untuk itu sosialisasi ini sesuai dengan target mitra agar dapat mengenal lebih dalam tentang berpikir komputasi.

Kegiatan dilanjutkan dengan pemaparan tim pengabdian yang menjelaskan teori dan konsep yang tercakup di dalam berpikir komputasi.

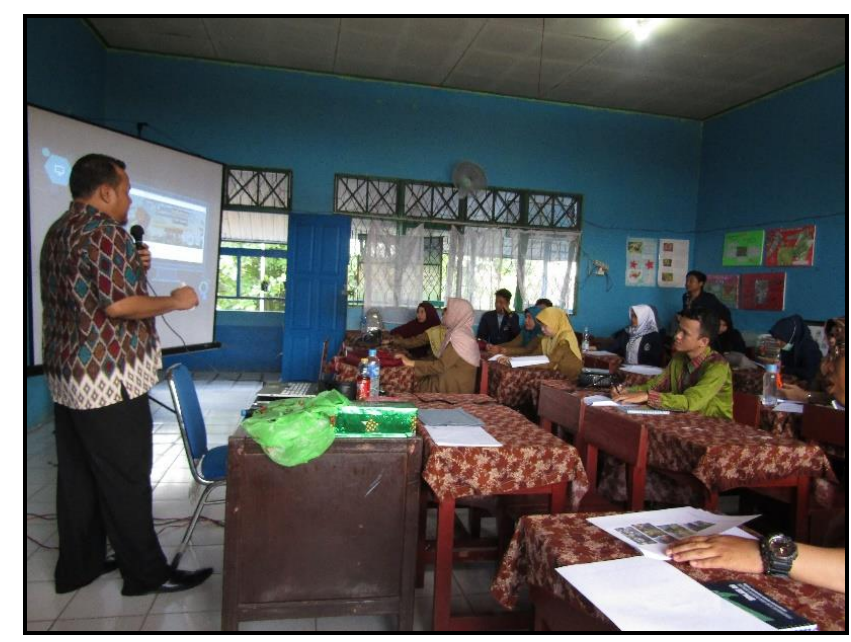

Gambar 1. Pemaparan teori Computational Thinking (berpikir komputasi)

Setelah pemaparan teori, kegiatan dilanjutkan dengan sesi praktik pembahasan contoh soal dan jawaban berpikir komputasi tingkat Sekolah Dasar (SD). Beberapa contoh soal diambil langsung dari laman bebras.or.id yang merupakan salah satu komunitas berpikir komputasi di Indonesia. Berikut salah satu contoh soal bebras untuk tingkat siaga (sekolah dasar) yang disampaikan pada sesi ini: Sara ingin membeli sepatu, dan ayahnya 
memberi batasan bahwa harganya tak boleh lebih dari Rp. 100.000,- rupiah. Sarah menyukai sepatu bot berwarna hitam. Sepatu mana yang dibeli oleh Sara? (Bebras Indonesia, 2018b).

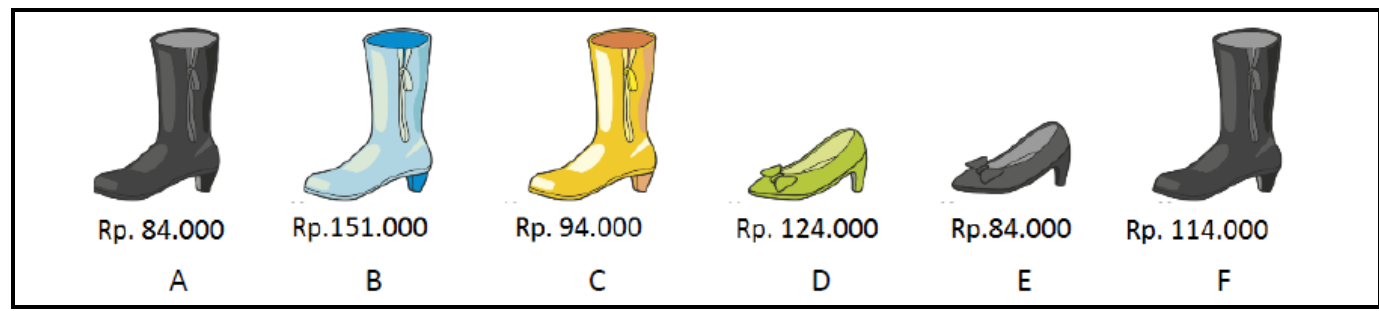

Gambar 2. Contoh soal Computational Thinking (berpikir komputasi)

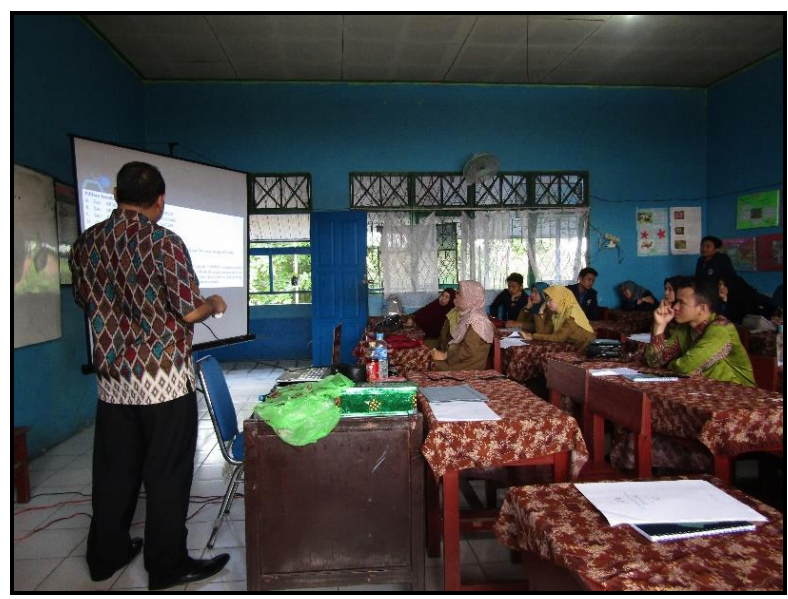

Gambar 3. Sesi praktik dan diskusi pengabdian

Para guru sangat antusias dalam mengikuti sesi praktik ini, mahasiswa yang dilibatkan juga sangat membantu dalam berinteraksi dan berdiskusi aktif dengan peserta pengabdian.

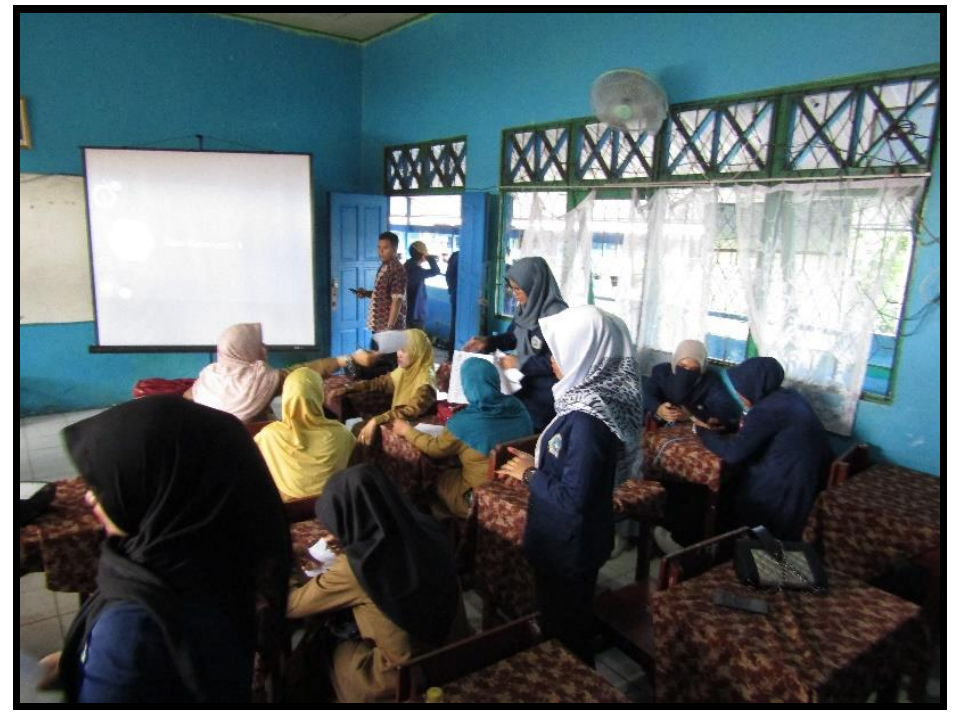

Gambar 4. Mahasiswa membantu peserta saat pelaksanaan pengabdian 
Pada sesi terakhir setelah sesi praktik dan diskusi, acara dilanjutkan dengan pengisian kuesioner setelah (pasca) pengabdian. Berbeda dengan kuesioner pra-pengabdian yang bertujuan untuk mengetahui pengetahuan umum peserta, kuesioner pasca-pengabdian ditujukan untuk mendapatkan hasil dan dampak pengabdian, dengan hasil sebagai berikut:

Tabel 2. Hasil kuesioner pasca-pengabdian

\begin{tabular}{ccc}
\hline Pertanyaan & Jawaban & Jumlah \\
Pemilih \\
\hline Computational Thinking wajib dikuasai oleh semua orang & Sangat Setuju & 5 \\
Somputational Thinking perlu diajarkan sejak tingkat Sekolah & Kurang Setuju & 0 \\
Dasar & Tidak Setuju & 1 \\
& Sangat Setuju & 5 \\
Saya ajarkan & Setuju & 9 \\
Computational Thinking dapat digunakan pada mata pelajaran yang & Kurang Setuju & 1 \\
Tidak Setuju & 0 \\
pada mata pelajaran yang saya ajar & Sangat Setuju & 3 \\
& Setuju & 10 \\
& Kurang Setuju & 2 \\
Tidak Setuju & 0 \\
Jumlah Peserta & Sangat Setuju & 1 \\
kepada guru-guru lain & Setuju & 12 \\
& Kurang Setuju & 2 \\
Tidak Setuju & 0
\end{tabular}

Dari tabel 2 didapatkan kesimpulan mayoritas peserta pengabdian setuju berpikir komputasi wajib dikuasai oleh semua orang, terutama pada era revolusi industri 4.0 sekarang ini. Mereka juga sepakat untuk menyisipkan materi berpikir komputasi ke dalam mata pelajaran masing-masing, walaupun masih ada 2 (dua) orang guru yang kurang setuju. Hal ini berkaitan dengan masih bingungnya guru tersebut pada bagian mana yang dapat disisipkan materi berpikir komputasi dan menyarankan ada pengabdian sejenis yang fokus pada materi pembuatan soal-soal berpikir komputasi.

\section{KESIMPULAN}

Dengan terlaksananya pengabdian kepada masyarakat ini, diharapkan guru-guru dapat menggunakan dan menyesuaikan materi berpikir komputasi (computational thinking) ke dalam masing-masing mata pelajaran yang mereka ampu. Metode ceramah yang menjelaskan pengertian, kegunaan dan manfaat berpikir komputasi menambah motivasi peserta untuk menerapkan computational thinking, dilanjutkan dengan praktik dan diskusi 
pembahasan soal membuat peserta mendapat gambaran lebih utuh mengenai berpikir komputasi. Hasil kuesioner setelah pengabdian didapatkan para guru telah memahami dan mengerti berpikir komputasi merupakan salah satu keahlian utama yang dapat menunjang kemampuan berpikir siswa dalam kehidupan sehari-hari dan sepakat bahwa contoh-contoh soal berpikir komputasi harus mulai ditambahkan dalam materi mata pelajaran.

\section{UCAPAN TERIMA KASIH}

Kami ucapkan terima kasih yang sebesar-besarnya kepada LPPM Universitas Islam Kalimantan Muhammad Arsyad Al Banjari Banjarmasin yang telah mendanai pengabdian kepada masyarakat ini, kepada Kepala Sekolah Dasar Negeri (SDN) Teluk Dalam 3 Banjarmasin selaku pimpinan mitra pengabdian dan semua guru yang telah berpartisipasi aktif saat pelaksanaan kegiatan pengabdian.

\section{DAFTAR PUSTAKA}

Bebras Indonesia. (2018a). Apa Itu Bebras? Retrieved from http://bebras.or.id/v3/

Bebras Indonesia. (2018b). Pembahasan Soal-Situs Resmi Bebras Indonesia. Retrieved from http://bebras.or.id/v3/pembahasan-soal/

Bebras Indonesia. (2018c). Pembahasan Soal - Situs Resmi Bebras Indonesia.

Calao, L. A., Leon, J. M., Correa, H. E., \& Robles, G. (2015). Developing Mathematical Thinking with Scratch An Experiment with 6th Grade Students. Design for Teaching and Learning in a Networked World, 17-27. https://doi.org/10.1007/978-3-31924258-3

Kementerian Pendidikan dan Kebudayaan. (2018). Data Referensi Pendidikan Kembdikbud. Jakarta: Kemendikbud.

Octavia, L. P. (2019). Media Pembelajaran dengan Gim Edukasi Berbasis Computational Thinking. Surakarta.

PISA. (2015). PISA 2015 Results: Executive Summary.

Prasetyo, H., \& Sutopo, W. (2018). Industri 4.0: Telaah Klasifikasi Aspek Dan Arah Perkembangan Riset. Jurnal Teknik Industri, 13(1), 17-26. https://doi.org/10.14710/jati.13.1.17-26

Sukamto, T. S., Pertiwi, A., Affandy, A., Syukur, A., Hafidhoh, N., \& Hidayat, E. Y. (2019). Pengenalan Computational Thinking Sebagai Metode Problem Solving Kepada Guru dan Siswa Sekolah di Kota Semarang. ABDIMASKU, 2(2), 99-107.

Syarifuddin, M., Risa, D. F., Hanifah, A. I., \& Nurussa'adah, N. (2019). Experiment Computational Thinking: Upaya Meningkatkan Kualitas Problem Solving Anak Melalui Permainan GORLIDS. Jurnal Mitra Pendidikan ( JMP Online ), 3(6), 807822.

Weintrop, D., Beheshti, E., Horn, M., Orton, K., Jona, K., Trouille, L., \& Wilensky, U. 
(2016). Defining Computational Thinking for Mathematics and Science Classrooms. Journal of Science Education and Technology, 25(1), 127-147. https://doi.org/10.1007/s10956-015-9581-5

Wijanto, M. C., Ayub, M., Senjaya, W. F., Toba, H., Santosa, S., Karnalim, O., ... Adelia. (2019). Evaluasi Pelaksanaan Tantangan Bebras untuk Siswa di Biro Universitas Kristen Maranatha pada tahun 2017 - 2018 untuk Edukasi Computational Thinking. Prosiding Seminar Nasional Hasil Pengabdian Kepada Masyarakat, 4(1), 295-301.

Wing, J. M. (2006). Computational Thinking. Communications of the ACM, 49(3), 33-35.

Wolfram, S. (2016). How to Teach Computational Thinking. Retrieved from https://writings.stephenwolfram.com/2016/09/how-to-teach-computational-thinking/ 